The patients who appeared to benefit most from the clinic were suffering from schizophrenia. Their reattendance rate was significantly higher than nonschizophrenic patients. Out of 63 schizophrenic patients, 30 became long attenders compared to 65 out of 197 non-schizophrenic patients $\left(\chi^{2}=5\right.$, $P<0.025)$. It was felt that the open access policy was pivotal in this respect. The mental state of many of these patients was stabilised or improved. It is likely that some would have deteriorated rapidly without psychiatric care, eventually requiring hospital admission. Of the chronic schizophrenic patients, 37 $(59 \%)$ had not been receiving psychiatric care for six months prior to their first consultation with us, suggesting that they had been lost to previous follow-up. Despite this about half became long attenders at our clinic.

Sixty-two per cent were initially managed at the clinic; $8 \%$ were admitted voluntarily to hospital; $8 \%$ to a detoxification unit and $5 \%$ to our sick bay. Over half of patients attended only once. There are many factors underlying this. Our non-prescribing policy for opiates and reluctance to prescribe benzodiazipines except on a short-term basis was undoubtedly unattractive to some. Others had only self-limiting problems, in particular those with neurosis or personality disorder in crisis, and follow-up in such cases would not be expected. However, we were also aware that some mentally ill homeless did not reattend more out of choice than for obvious external reasons. It is also likely that despite the ease of access to our clinic some homeless would still not attend.

It is not unique for psychiatrists to work in a general practice setting and this is usually found to be satisfactory. This system has many advantages in dealing with the single homeless. Referrals can be made quickly to a psychiatrist who is personally known to the staff. The familiarity of the patients with the medical centre and its staff helps to reduce their fear of meeting a psychiatrist as he is seen as being part of the same team. Patients are sometimes reluctant to be referred to a psychiatric outpatient clinic. The informality of our clinic avoids some of these problems including the feeling of stigmatisation felt at seeing a psychiatrist in a hospital.

\section{Comment}

A drop-in psychiatric clinic, based on a pragmatic, flexible and responsive approach can significantly enhance the quality of medical service offered to the single homeless in a primary care setting. Schizophrenic patients in particular appear to benefit. The model may be replicable in other centres.

\section{References}

EL-KABIR, D. J. (1982) Great Chapel Street Medical Centre. British Medical Journal, 284, 1679.

LODGE-PATCH, I. C. (1971) Homeless men in London. 1. Demographic findings in a lodging house sample. British Journal of Psychiatry, 118, 313-317.

SCOTt, R., GASKell, P. \& Morrell, D. C. (1966) Patients who reside in common lodging houses. British Medical Journal, ii, 1561-1564.

Tidmarsh, D. \& WoOD, S. (1972) Psychiatric aspects of destitution. In Evaluating a Community Psychiatric Service: The Camberwell Register 1964-1971 (eds. J. K. Wing and A. M. Hailey). Oxford: Oxford University Press.

TYRER, P. (1984) Psychiatric clinics in general practice. British Journal of Psychiatry, 145, 9-14.

\title{
Consumer satisfaction with a psychiatric out-patient clinic
}

\section{A. JAWAD SheikH, Senior Registrar; and Christopher MEAkIn, Senior Registrar, Midland Nerve Hospital, Elvetham Road, Edgbaston, Birmingham B15 2NJ}

NHS out-patient clinics remain a major point of contact between psychiatrists and their patients. There are several advantages to this setting for consultation: it is time efficient, there is usually easy access to case records and contact with other disciplines and services is often available. With the 
current trend towards community care, increasing use of out-patient facilities is likely as home visiting becomes impractical and, moreover, may be undesirable for some patients.

But what is it like to attend an NHS clinic? It seems that patients (and their doctors) frequently have prejudices and misconceptions about psychiatric consultation (Burgess \& Harrington, 1964; Clare, 1983; Skuse, 1975). However, the actual experience of attendance at a clinic has been little researched. The present study was designed to give insight into this experience, which might in turn suggest whether modifications in the everyday practice of clinic work are needed.

\section{The study}

A questionnaire was given to 50 consecutive new patients and 100 follow-up patients on their attendance at an NHS teaching hospital general psychiatric out-patient department. This was to be completed anonymously and returned by post, using the stamped addressed envelope provided. A mixture of forced choice items and open-ended ones was used as it was felt that this would provide the most comprehensive coverage of the patients' viewpoints. Questions related to the practical aspects of clinic attendance as well as the experience of the consultation. A blank sheet was provided with an instruction to use it if necessary. All clinics studied were based in one out-patient suite with the same reception and general organisation. Most questionnaires were given to attenders at five general adult psychiatric clinics and a pregnancy-related disorders clinic per week. These clinics were under the care of three consultants and involved five other doctors. Most new cases were seen by a medical student or junior doctor and then seen by a senior registrar or consultant. Some attenders at an occasional fourth consultant clinic were involved, as well as a few attenders at two clinical assistant psychotherapy clinics.

\section{Findings}

Questionnaires were returned by $23(46 \%)$ of the new patients and $60(60 \%)$ of the follow-ups. Results from the forced choice items are presented in Table I.

The department itself was on the fifth floor of a general hospital and was difficult to find, as were parking spaces. These problems were commented on by 10 out of $83(12 \%)$ attenders. Not surprisingly, the follow-up patients found it easier to get to the clinic. The reception staff were popular, with extra praise for courtesy, friendliness and related attributes from $50(60 \%)$ attenders. Criticisms were mostly constructive and were made by $25(30 \%)$ attenders. Apart from suggestions for improved signposting and parking, there were a few requests for a drinks machine, reassurance when undue waiting occurred and a no smoking policy. Opinions as to the standard of decor were infrequent and inconsistent. In terms of location of the consultation, the majority of attenders would rather not have been seen at home (see Table I).

Nearly half of first-time attenders had to wait more than four weeks for an appointment, but only one said that the appointment should have been sooner. Most people felt that they knew the grade of at least one of the doctors who saw them, the list including the category of medical student. Of the 17 people who did not know the grade of anyone who saw them, $10(59 \%)$ said that they saw who they expected to see, presumably reflecting preconception about doctors' anonymity in NHS clinics. A minority would have liked to have been seen by someone else, usually a consultant or the professor, although there was one request for a female doctor.

The content of the consultation was usually felt to be good. Criticisms about the style of the interview were made by 14 out of 83 attenders $(17 \%)$ and were largely requests for more time to be taken. Two out of 17 attenders who said they had seen a medical student would have preferred not to have done. Two of the follow-up patients requested that they should see the same doctor each time. Good features of the interview were mentioned by 18 out of 23 new patients (78\%), and 39 out of 60 follow-up patients $(65 \%)$. These all had the general content of 'being taken seriously'; for example the doctor listening, being interested, being thorough and spending time with the patient. Plans for future care were generally felt to be good. It was suggested by four out of the 83 that rapid contact should be available if required. Ongoing contact was mentioned as being important by 18 out of the 83 attenders $(22 \%)$.

Views of the attenders about the interviewing of relatives were sought. Eleven (18\%) of the follow-up patients made no comment about this, while the other $82 \%$ agreed with it. Of the new cases, $27 \%$ made no comment, $59 \%$ agreed and $14 \%$ objected. Four of the whole group said that relatives should only be interviewed with their consent.

\section{Comment}

The modest response rate in this study and generally favourable comments might imply that some disenchanted or poorly motivated individuals were excluded, with resultant bias. On the other hand, the total anonymity would have encouraged people to be frank. This, combined with a lack of irate remarks, suggests that the clinic was felt by the clients to be providing a reasonable service. Overall, we were surprised with the degree of satisfaction expressed by the respondents. 
TABLE I

Percentage distribution of forced choice questionnaire items

\begin{tabular}{|c|c|c|c|c|}
\hline If this is your first visit, & $\begin{array}{c}\text { appointment? } \\
\text { less than } \\
2 \text { weeks } \\
35 \%\end{array}$ & $\begin{array}{c}2-4 \text { weeks } \\
17 \%\end{array}$ & $\begin{array}{c}\text { more than } \\
4 \text { weeks } \\
48 \%\end{array}$ & $\begin{array}{c}n \\
23\end{array}$ \\
\hline \multicolumn{5}{|l|}{ How did you find: } \\
\hline \multicolumn{5}{|l|}{ getting to the clinic? } \\
\hline $\begin{array}{l}\text { new patients } \\
\text { follow-ups }\end{array}$ & $\begin{array}{l}26 \% \\
47 \%\end{array}$ & $\begin{array}{l}52 \% \\
43 \%\end{array}$ & $\begin{array}{l}22 \% \\
10 \%\end{array}$ & $\begin{array}{l}23 \\
58\end{array}$ \\
\hline \multicolumn{5}{|l|}{ reception at the clinic? } \\
\hline new patients & $91 \%$ & $9 \%$ & $0 \%$ & 23 \\
\hline follow-ups & $87 \%$ & $13 \%$ & $0 \%$ & 56 \\
\hline \multicolumn{5}{|l|}{ waiting room facilities? } \\
\hline $\begin{array}{l}\text { new patients } \\
\text { follow-ups }\end{array}$ & $\begin{array}{l}61 \% \\
70 \%\end{array}$ & $\begin{array}{l}39 \% \\
28 \%\end{array}$ & $\begin{array}{l}0 \% \\
2 \%\end{array}$ & $\begin{array}{l}23 \\
56\end{array}$ \\
\hline \multicolumn{5}{|c|}{ How long after your appointment time did you wait to be seen? } \\
\hline & $\begin{array}{l}\text { less than } \\
15 \text { minutes }\end{array}$ & $\begin{array}{c}15-30 \\
\text { minutes }\end{array}$ & $\begin{array}{l}\text { more than } \\
30 \text { minutes }\end{array}$ & $\mathbf{n}$ \\
\hline new patients & $56 \%$ & $35 \%$ & $\mathbf{9 \%}$ & 23 \\
\hline follow-ups & $61 \%$ & $28 \%$ & $11 \%$ & 57 \\
\hline
\end{tabular}

If you had the choice, would you rather be seen (a) at a hospital clinic; (b) at a clinic based at your family doctor's premises; or (c) at home?

\begin{tabular}{lcccc} 
& $(a)$ & $(b)$ & $(c)$ & $n$ \\
new patients & $33 \%$ & $38 \%$ & $29 \%$ & 2 \\
follow-ups & $65 \%$ & $12 \%$ & $23 \%$ & 52 \\
\hline
\end{tabular}

What grade of doctor were you seen by?

new patients

follow-ups
circled at least
one on list
$78 \%$
$78 \%$

$\begin{array}{cc}\text { circled don't } & \\ \text { know } & \mathrm{n} \\ 22 \% & 23 \\ 22 \% & 58\end{array}$

Was this who you expected to see?

$\begin{array}{lccc} & \text { yes } & n o & n \\ \text { new patients } & 74 \% & 26 \% & 23 \\ \text { follow-ups } & 90 \% & 10 \% & 58\end{array}$

Would you like to have been seen by someone else?

new patients

yes $\quad$ no $\quad$ n

follow-ups

$12 \%$

$88 \%$

How useful did you find the consultation?

new patients

follow-ups

good

$78 \%$

$63 \%$

$\begin{array}{ccc}\text { satisfactory } & \text { unsatisfactory } & \text { n } \\ 22 \% & 0 \% & 23 \\ 32 \% & 5 \% & 57\end{array}$

Are the plans for your future care:

new patients

follow-ups

$\begin{array}{lccc}\text { good } & \text { satisfactory } & \text { unsatisfactory } & \text { n } \\ 65 \% & 35 \% & 0 \% & 20 \\ 58 \% & 32 \% & 10 \% & 57\end{array}$


Some interesting light was thrown on the experience of the patient during the consultation itself. In the answers to open-ended questions about this, there were virtually no comments relating to 'insightful' experiences. One person wanted 'more interpretation', but apart from this example, there was little to suggest that patients expected much more than to be taken seriously in a traditional doctor-patient relationship. The overwhelming preference was for a courteous and efficient reception followed by an unhurried and thorough consultation. Obviously, a conflict may exist between the expectation of the patient and his management by the doctor. The latter is likely to be short of time and furthermore attempting to avoid reinforcement of illness behaviour. Surprisingly, good listening skills seemed rather more important than the grade of doctor or being seen by the same doctor each time. In view of time constraints on the clinic, it was reassuring that only $13 \%$ of the total sample would have preferred a longer consultation.

As to the venue of the consultation, the responses of the new patients are probably most meaningful. Seventy-one per cent were in favour of a clinic setting, with just over half of these preferring this to be at their family doctor's premises were this option available. We feel that this would only be practicable if a large health centre were available which catered for a sizeable proportion of the catchment population. A recent development is that of a community resource centre clinic, which may offer a good blend of facilities and accessibility.

\section{Acknowledgement}

We wish to thank the staff at the clinic involved in this study for their cooperation.

\section{References}

Burgess, J. \& HarRington, J. (1964). Two hundred psychiatric out-patient non-attenders. Case Conference, 11, 59-60.

Clare, A. W. (1983). Use and abuse of the psychiatric consultation. Medicine International, 1, 1579-1581.

SkUSE, D. H. (1975). Attitudes to the psychiatric outpatient clinic. British Medical Journal, 3, 469-471.

The questionnaire employed is available on request from the authors.

\section{GASKELL Royal College of Psychiatrists Lectures on the History of Psychiatry}

\section{The Squibb Series}

Edited by R. M. Murray \& T. H. Turner

"There are only a limited number of theories which we use in psychiatry, just as there are a limited number of basic variables in painting or music or sculpture." James Birley, Chapter 1, The history of psychiatry as the history of an art

"With regard to the beating with rods part, I would only comment that, since this was considered to be one of the appropriate remedies for insanity at the time when the law was formulated, it must be interpreted in this light, rather than as a punishment per se." Patricia Allderidge, Chapter 3, Hospitals, madhouses and asylums: cycles in the care of the insane

"Before the middle of the 17 th century most men and women believed that perfectly rational people could receive inspiration from God or have intercourse with the Devil." Michael MacDonald, Chapter 5, Insanity and the realities of history in early modern England

\section{$£ 10,236$ pp, ISBN $090224132 \mathrm{X}$}

"What emerged was a formula whereby addiction, clearly not simply a physical disease, became a 'disease of the will'. It was disease and vice." Virginia Berridge, Chapter 7, Opium and the doctors: disease theory and policy

"Wharton ... ached to meet the fairies; all the more so because Mary Parish assured him that through the Lowlanders' good offices, they would locate and liberate untold stores of buried treasure. Moreover, Mary soon hinted, Penelope, the Queen of the Fairies, had taken quite a fancy to him." Roy Porter, Chapter 9, The diary of a madman, 17th-century style: Goodwin Wharton, MP and communer with the fairy world

"But they did find that 'some patients had a very decided liking for bicycle polo. The latter is a really valuable agent, as it needs such skill and direct attention to the game that their mental idiosyncracies had little scope for action'." Trevor Turner, Chapter 11, Rich and mad in Victorian England 